\title{
Apolipoprotein $\mathrm{Cl}$ (APOCl) promotes tumor progression via MAPK signaling pathways in colorectal cancer
}

This article was published in the following Dove Press journal: Cancer Management and Research

\author{
Hui Ren ${ }^{1,2, *}$ \\ Zhihui Chen ${ }^{1, *}$ \\ Liang Yang ${ }^{1} *$ \\ Weixin Xiong' \\ Hong Yang ${ }^{3}$ \\ Kaiwu Xu ${ }^{1}$ \\ Ertao Zhai ${ }^{1}$ \\ Li Ding ${ }^{4}$ \\ Yulong $\mathrm{He}^{1,2}$ \\ Xingming Song'
}

'Department of Gastrointestinal Surgery Centre, First Affiliated Hospital, Sun Yatsen University, Guangzhou, People's Republic of China; ${ }^{2}$ Center for Digestive Disease, Seventh Affiliated Hospital, Sun Yat-sen University, Shenzhen, People's Republic of China; ${ }^{3}$ Department of Operating Room, First Affiliated Hospital, Sun Yat-sen University, Guangzhou, People's Republic of China; ${ }^{4}$ Department of Pathology, First Affiliated Hospital, Sun Yat-sen University, Guangzhou, People's Republic of China

*These authors contributed equally to this work

\begin{abstract}
Aim: Identifying high-efficiency prognostic markers for colorectal cancer (CRC) is necessary for clinical practice. Increasing evidence demonstrates that apolipoprotein C1 (APOC1) promotes carcinogenesis in some human cancers. However, the expression status and biological function of APOC1 in CRC remain unclear.
\end{abstract}

Materials and methods: We detected the association between APOC1 expression and clinicopathological features in $140 \mathrm{CRC}$ patients by immunohistochemistry. Small interfering RNA (siRNA) technology was used to downregulate APOC1 expression in CRC cells. Cell proliferation was estimated by CCK 8 and clonogenic assays. The cell cycle and apoptosis were analyzed by flow cytometry. Cell migration and invasion were examined by a transwell assay. Gene set enrichment analysis (GSEA) and protein expression of signaling pathways were used to suggest the possible APOC1-associated pathways in CRC.

Results: APOC1 was highly expressed in CRC tissues. High immunohistochemistry (IHC) expression of APOC1 was correlated with the N stage, M stage and TNM stage. High IHC APOC1 expression in CRC tissues was associated with poor prognosis. Univariate and multivariate Cox regression analyses showed that APOC1 was an independent risk factor for OS. Cell proliferation of CRC cell lines was inhibited by the downregulation of APOC1. Moreover, si-APOC1 transfection induced cell cycle arrest but low apoptosis increases by regulating the expression of related proteins. Cell migration and invasion were also inhibited by the downregulation of APOC1. The Cancer Genome Atlas Colorectal Adenocarcinoma (TCGA COAD-READ) dataset analyzed by GSEA showed that APOC1 might be involved in the mitogen-activated protein kinase (MAPK) signaling pathway, which was further preliminarily confirmed by Western blotting.

Conclusion: APOC1 was overexpressed in CRC tissues, and a high level of APOC1 contributed to a poor prognosis. APOC1 expression influenced the cell proliferation ability and motility capacity of CRC via the MAPK pathway. APOC1 could act as a novel prognostic biomarker in CRC.

Keywords: apolipoprotein $\mathrm{C} 1$, APOC1, colorectal cancer, prognosis, MAPK signaling

\section{Introduction}

Colorectal cancer (CRC) is the third most common malignant tumor and is the fourth leading cause of death from cancer worldwide. ${ }^{1,2}$ The morbidity and mortality of CRC have been increasing in recent years. ${ }^{3}$ Despite the advance in early detection, chemotherapy, surgery and target therapy, the prognosis of patient with advanced CRC remains poor. CRC development is a multistep process with the accumulation of genetic and epigenetic alterations. Therefore, it is important to
Correspondence: Xingming Song Department of Gastrointestinal Surgery Centre, First Affiliated Hospital, Sun Yatsen University, No. 58 Zhongshan 2nd Road, Guangzhou 510080, People's

Republic of China

Tel +86208775 5766

Email songxm@mail.sysu.edu.cn 
clarify the molecular mechanisms controlling CRC progression and explore novel targeted drugs for improving the prognosis of $\mathrm{CRC}$ patients.

Apolipoprotein C1 (APOC1), a producer gene located at $19 \mathrm{q} 13.32$, belongs to the apolipoprotein $\mathrm{C}$ family. The protein is mainly synthesized by the liver and other tissues such as the brain, lung, spleen and intestines. ${ }^{4}$ APOC1 participates in lipoprotein metabolism by regulating the expression of lipase, transferases and cholesteryl ester transfer protein (CETP) and inhibiting the uptake of triglyceride lipoprotein by the hepatic lipoprotein receptor. However, in recent years, some studies have confirmed that APOC1 promotes carcinogenesis and tumor development. ${ }^{5-7}$ APOC1 is highly expressed in late-stage lung cancer and is likely involved in the progression of the tumor burden. In papillary thyroid carcinoma, APOC1 can be considered a candidate prognostic biomarker for patients with papillary thyroid carcinoma. ${ }^{8}$ However, the role of APOC1 in CRC progression has not been revealed.

APOC1 is a type of secretory protein commonly associated with very low-density lipoprotein(VLDL) and lowdensity lipoprotein (LDL). ${ }^{9,10}$ Recent studies showed that LDL can regulate cell proliferation, migration and apoptosis and induce cell inflammation via MAPK signaling pathways. ${ }^{11-14}$ MAPK signaling pathways participated in a wide range of complex biologic processes, such as cell proliferation, cell death, cell migration and cell invasion. ${ }^{15-17}$ MAPKs are a group of serine-threonine kinases that mediate a wide variety of cellular behaviors in response to extracellular stimuli. ${ }^{18}$ The foremost enzymes studied in the MAPK family include the extracellular signal-regulated kinases 1 and 2 (ERK1/2), c-Jun amino-terminal- kinase 1-3 (JNK 1/2/3) and p38MAPK.

In this study, we first detected APOC1 expression in CRC tissues and analyzed its clinical significance in patients with CRC. Then, we investigated the role of APOC1 on cell proliferation, apoptosis, migration and invasion in CRC cell lines. Furthermore, by analyzing the data from TCGA cohorts, we determined that APOC1regulated CRC progression by activating the P38 MAPK signaling pathway. Our study demonstrates that APOC1 could be a prognostic factor in CRC.

\section{Materials and methods}

\section{Patients and tissue samples}

A total of 140 cases of CRC paraffin-embedded samples and 15 paired fresh CRC samples were enrolled in this study. All samples were obtained from CRC patients undergoing colorectal surgery at the Gastroenterology of the First Affiliated Hospital of Sun Yat-sen University (FAHSYSU) in 2010 and 2017. The 140 paraffinembedded samples were used for immunohistochemistry and histological evaluation. The patient's demographic and clinicopathological features are shown in Supplemental Table 1. The CRC TNM status was applied according to guidelines from the 2017 American Joint Committee on Cancer staging manual (AJCC 8th edition). All patients had follow-up records of more than 5 years between 2010 and 2017. Survival time was measured from the date of surgery to the follow-up deadline or date of death (usually the result of cancer recurrence or metastasis). Another 15 paired fresh samples obtained in 2017 were used for immunohistochemistry, protein and RNA expression analysis. In addition, no patient received preoperative chemotherapy or radiotherapy. All patients had provided a written informed consent by the First Affiliated Hospital of Sun Yat-sen University Institutional Review Board for the use of these clinical materials for research purposes. And this study was conducted in accordance with the Declaration of Helsinki.

\section{Immunohistochemistry (IHC)}

The following procedures were performed by classical biotin-streptavidin-peroxidase IHC staining protocols according to previously described methods. ${ }^{19}$ Briefly, the protein expression of APOC1 was detected by anti-APOC1 (1:200, ab198288, Abcam Inc, Cambridge, MA, USA) antibody and a goat anti-mouse/rabbit secondary antibody (Gene Tech Co Ltd, GTVisionTM III Detection System/Mo\&Rb, Shanghai, China). To estimate the score for the 140 cases of CRC paraffin-embedded samples, five high-power fields were chosen randomly for the assessment of APOC1 expression in a double-blind procedure. The sample scores were based on both the intensity of staining and the proportion of positively stained tumor tissue. The immunostaining results were scored based on the following system: for staining intensity scoring: 0 (negative), 1 (weak), 2 (moderate), 3 (strong); for staining area scoring: $0(0 \%), 1$ (1-25\%), 2 (26-50\%), $3(51-75 \%)$ and 4 (76-100\%). The staining index was calculated as the product of the proportion of positive tissue $\times$ the staining intensity score (range from 0 to 12). An optimal cutoff value was identified as follows: a staining index score $\geq 6$ was considered as tumors with high APOC1 expression and $\leq 4$ was considered as tumors with low expression of APOC1. ${ }^{20}$ 
Table I Relationship between Apolipoprotein CI (APOCI) expression and clinicopathological features in I40 colorectal cancers

\begin{tabular}{|c|c|c|c|c|c|}
\hline Characteristics & Number & Low expression $(\mathrm{N}=73)$ & High expression $(\mathrm{N}=67)$ & $\chi^{2}$ & $p$-Value \\
\hline Gender & & & & 0.162 & 0.688 \\
\hline Male & 86 & 46 & 40 & & \\
\hline Female & 54 & 27 & 27 & & \\
\hline Age & & & & 1.148 & 0.284 \\
\hline$<60$ years & 63 & 36 & 27 & & \\
\hline$\geq 60$ years & 77 & 37 & 40 & & \\
\hline Tumor size & & & & 0.029 & 0.866 \\
\hline$<5 \mathrm{~cm}$ & 70 & 36 & 34 & & \\
\hline$\geq 5 \mathrm{~cm}$ & 70 & 37 & 33 & & \\
\hline Differentiation degree & & & & 5.076 & 0.079 \\
\hline Well & 7 & 6 & I & & \\
\hline Morderate & 105 & 56 & 49 & & \\
\hline Poor & 28 & 11 & 17 & & \\
\hline Tumor location & & & & 0.885 & 0.927 \\
\hline Ascending colon & 30 & 16 & 14 & & \\
\hline Transverse colon & 8 & 4 & 4 & & \\
\hline Descending colon & 7 & 3 & 4 & & \\
\hline Sigmoid colon & 26 & 12 & 14 & & \\
\hline Rectum & 69 & 38 & 31 & & \\
\hline T stage & & & & 3.987 & 0.263 \\
\hline I & 3 & 3 & 0 & & \\
\hline 2 & 22 & 13 & 9 & & \\
\hline 3 & 107 & 54 & 53 & & \\
\hline 4 & 8 & 3 & 5 & & \\
\hline N Stage & & & & 5.983 & $0.05^{\mathrm{a}}$ \\
\hline 0 & 85 & 50 & 35 & & \\
\hline I & 37 & 18 & 19 & & \\
\hline 2 & 18 & 5 & 13 & & \\
\hline M stage & & & & 5.876 & $0.015^{\mathrm{a}}$ \\
\hline 0 & 121 & 68 & 53 & & \\
\hline I & 19 & 5 & 14 & & \\
\hline TNM stage & & & & 8.734 & $0.033^{\mathrm{a}}$ \\
\hline I & 20 & 14 & 6 & & \\
\hline II & 57 & 33 & 24 & & \\
\hline III & 44 & 21 & 23 & & \\
\hline IV & 19 & 5 & 14 & & \\
\hline
\end{tabular}

Notes: Statistical analyses were performed by the Pearson $\chi 2$ test. The TNM staging system is based on the extent of the tumor (T), the extent of spread to the lymph nodes $(\mathrm{N})$ and the presence of metastasis $(\mathrm{M})$. ${ }^{\mathrm{a} S}$ Statistically significant.

\section{Cell culture and treatment}

Human CRC cell lines (SW1116, SW620, HCT116, SW480 and LS174T) were obtained from the American Type Culture Collection (Manassas, VA, USA). NCM460, a human immortalized colonic epithelial cell line, was obtained from IN CELL (San Antonio, TX, USA). All cell lines were cultured at $37^{\circ} \mathrm{C}$ with 5\% $\mathrm{CO}_{2}$ in DMEM/RPMI-1640 medium (Gibco, Thermo Fisher Scientific, Waltham, MA, USA) supplemented with
10\% FBS (Gibco, Thermo Fisher Scientific, Waltham, MA, USA), $100 \mathrm{U} / \mathrm{mL}$ penicillin and $100 \mu \mathrm{g} / \mathrm{mL}$ streptomycin.

\section{Cell transfection with small interfering RNA (siRNA)}

To knock down the expression of APOC1, three APOC1targeted siRNAs (si-APOC1\#1-3) and a negative control siRNA (si-Control) synthesized by GenePharma (RiboBio, 
Guangzhou, China) were used. The siRNA sequences are shown in Table S1. SW480 and SW620 cells were transiently transfected with siRNAs using Lipofectamine 3000 (Invitrogen, Carlsbad, CA, USA) according to the manufacturer's instructions. The transfected cells were designated as SW480/si-APOC1, SW480/si-Control, SW620/si-APOC1 and SW620/si-Control, respectively.

\section{RNA extraction, reverse transcription and real-time quantitative PCR}

Total RNA was extracted from cultured cells or tissues using Trizol reagent (Invitrogen, Carlsbad, CA, USA) according to the manufacturer's instructions. Real-time quantitative PCR was performed using SYBR Green I (Invitrogen) with an ABI PRISM 7500 system (Applied Biosystems, Foster City, CA, USA). The housekeeping gene GAPDH (glyceraldehyde-3-phosphate dehydrogenase) was used as an internal control. Primers for realtime quantitative PCR are summarized in Table S2.

\section{Western blotting}

Western blotting was performed as previously described. ${ }^{21}$ The following primary antibodies were used: APOC1 (1:1000, ab198288), cyclin B1 (1:5000, ab32053), cyclin D1 (1:5000, ab134175), caspase-9 (1:1000, ab202068), BCL-2 (1:500, ab32124), ERK1/2 (1:500, ab196883), phospho-ERK1/2 (1:500, ab65142), and GADPH (1:2500, ab9485) were purchased from Abcam Inc. Phospho-p38 (1:1000, \#9211), p38 (1:1000, \#9212), phospho-JNK $(1: 1000, \# 9251)$ and JNK $(1: 1000, \# 9252)$ were purchased from Cell Signaling Technology (Boston, MA, USA). Goat anti-rabbit IgG H\&L (1:2000, ab6721, Abcam) was used as a second antibody.

\section{Cell proliferation detection}

Cell proliferation detection was assessed by the Cell Counting Kit-8 (CCK-8) cell proliferation kit (Dojindo Laboratories, Kumamoto, Japan) according to the manufacturer's instructions. Briefly, cells were plated into 96well plates at $2 \times 10^{3}$ cells/well with $100 \mu \mathrm{L}$ complete medium and cultured under normal conditions. At the indicated times, cells were incubated with $100 \mu \mathrm{L}$ of RPMI-1640 medium plus $10 \mu \mathrm{L}$ of CCK 8 reagent at $37^{\circ} \mathrm{C}$ for $2 \mathrm{hrs}$. Then, the absorbance was measured on a microplate reader (Bio-Rad, La Jolla, CA, USA) at a wavelength of $450 \mathrm{~nm}$. Three independent repeat experiments were performed.

\section{Flow cytometry analysis of the cell cycle and apoptosis}

Flow cytometry analysis was performed as previously described. ${ }^{22}$ For cell cycle analysis, the cells were trypsinized and washed into single-cell suspensions and fixed with ice-cold $70 \%$ ethanol at $-20^{\circ} \mathrm{C}$ overnight. The fixed cells were then subsequently stained with $20 \mathrm{mg} / \mathrm{mL}$ propidium iodide (PI) staining buffer (containing 1\% Triton $\mathrm{X}-100$ and $100 \mathrm{mg} / \mathrm{mL}$ RNase A) for $30 \mathrm{mins}$. DNA content was assessed using a FACSCalibur unit (Becton Dickinson, Franklin Lakes, NJ, USA) equipped with ModFit LT v2.0 software. To analyze apoptosis, cultured cells were harvested by trypsinization and were washed with PBS. Cells $\left(1 \times 10^{6}\right)$ from each sample were processed for annexin V-fluorescein isothiocyanate (FITC)/PI apoptosis detection according to the manufacturer's instructions (Becton Dickinson, Franklin Lakes, NJ, USA). All the experiments were repeated at least three times.

\section{Colony formation assay}

Briefly, exponentially growing cells were seeded into 6-well plates (1000 cells/well) and cultured at $37^{\circ} \mathrm{C}$ with $5 \% \mathrm{CO}_{2}$ for 10-14 days. The colonies were fixed with $75 \%$ ethanol for $30 \mathrm{mins}$ and then were stained with $0.5 \%$ crystal violet (Beyotime, Nanjing, China) for visualization and counting. Only colonies with more than 50 cells were counted manually. Triple wells were included for each group of cells, and all experiments were repeated three times.

\section{Transwell migration and invasion assays}

Cell transwell migration and invasion assays were performed using a transwell apparatus (Corning, NY, USA) with the upper chamber of an 8 - $\mu \mathrm{m}$ pore size polycarbonate membrane placed in matched 24-well cell culture plates. For the migration assay, cells $\left(1 \times 10^{5}\right)$ in $200 \mu \mathrm{L}$ RPMI-1640 were seeded into the upper chamber without Matrigel; for the invasion assay, cells $\left(2 \times 10^{5}\right)$ in $200 \mu \mathrm{L}$ RPMI-1640 were seeded into the upper chamber with a thin layer of $0.5 \mathrm{mg} / \mathrm{L}$ Matrigel (BD Biosciences, Franklin Lakes, NJ, USA). For both assays, $500 \mu \mathrm{L}$ RPMI-1640 containing 20\% FBS was added to the lower chambers. The plates were incubated for $24 \mathrm{hrs}$ (migration) or $48 \mathrm{hrs}$ (invasion). Then, cells that had migrated or invaded to the bottom of the membrane were fixed with $75 \%$ methanol for 30 mins and stained with $0.5 \%$ crystal violet for $1 \mathrm{hr}$. Cells were counted in 5 random fields for each membrane under a microscope (Axio Observer Z1, 
ZEISS, Germany) at $100 \times$ magnification. Each measurement was carried out in triplicate wells, and independent experiments were repeated three times.

\section{Bioinformatics analysis}

We collected gene expression data for 380 colon and rectal adenocarcinomas (COAD-READ) and 50 normal tissues cases from The Cancer Genome Atlas website (TCGA, https://tcga-data.nci.nih.gov/tcga/). To investigate the molecular pathways associated with overexpression of APOC1 in CRC, gene set enrichment analysis (GSEA) ${ }^{23}$ was performed using the GSEA desktop software. ${ }^{24}$ Enriched gene sets comparing APOC1 higher expression and lower expression were identified using 1,000 permutations of the phenotype labels. We also used Oncomine (https://www.oncomine.org), a database of RNA and DNA sequencing information curated from The Cancer Genome Altas, Gene Expression Omnibus and other published literature to evaluate and compare the expression level of APOC1 between CRC and normal samples.

\section{Statistical analysis}

The results are expressed as mean $\pm \mathrm{SD}$. All statistical analyses were performed using the SPSS statistical software package (standard V.20.0; IBM Corportion, Armonk, USA.). Pearson's Chi-square test was used for comparison of patient clinicopathological characteristics with APOC1 expression. A Cox regression proportional hazards model was used for univariate and multivariate analyses to determine the independent significance of relevant clinical covariates. The association of APOC1 expression and overall survival (OS) rates of patients were calculated by the Kaplan-Meier method, and differences were analyzed using the log-rank test. Values of $P<0.05$ in all cases were considered statistically significant.

\section{Results \\ $\mathrm{APOCl}$ is overexpressed in primary CRC}

To evaluate APOC1 expression in CRC and normal tissues, we first analyzed APOC1 expression in the TCGA cohort (Figure 1A and B). The upregulation of APOC1 mRNA was validated in CRC samples $(\mathrm{N}=380)$ compared to normal samples $(\mathrm{N}=50)$ from the TCGA cohorts $(P=0.012)$ (Figure 1A). A similar trend was observed in paired tumor and adjacent normal samples in the same cohort $(\mathrm{N}=25 ; P=0.002)$ (Figure 1B). We also found that APOC1 mRNA expression was upregulated in different
Oncomine CRC cohorts ${ }^{25-29}$ (Table 2). We then evaluated the mRNA and protein expression levels of APOC1 in 15 paired CRC and adjacent normal fresh samples by qPCR and Western blots. The mRNA levels were significantly elevated in the CRC tissues compared to the matched adjacent normal tissues $(P<0.05$, Figure 1C). Consistent with these results, the protein expression level of APOC1 in Case 1 to Case 4 was significantly lower in the adjacent normal tissues $(\mathrm{N})$ compared with the matched CRC tissues $(\mathrm{T})$ as shown in Western blots (Figure 1D).

To estimate the relation between APOC1 expression and clinicopathological features, 140 cases of paraffin-embedded samples from patients with CRC were analyzed using immunohistochemistry staining. All patients with CRC were divided into two groups (APOC1 high or low expression) by the cutoff value that was established by immunohistochemistry. APOC1 protein expression was distributed in the cytoplasm of CRC tumor cells, but was negative in normal colon tissue cells (Figure 1E). As shown in Table 1, there was no correlation between APOC1 expression and clinicopathological features such as gender, age, tumor size, differentiation degree and tumor location, while high expression of APOC1 was significantly positively associated with $\mathrm{N}$ stage $(P=0.05)$, $\mathrm{M}$ stage $(P=0.015)$ and TNM stage $(P=0.033)$. Thereafter, the Kaplan-Meier method was used to determine the effect of APOC1 expression on patient survival. The data showed that patients with high IHC expression of APOC1 had significantly shorter OS than others $(P=0.005$, log-rank test) (Figure $1 \mathrm{~F})$. The diseasefree survival (DFS) results were similar (Figure 1G). Moreover, in univariate Cox regression analysis, high expression of APOC1 was significantly associated with poor OS and DSF with a HR of $2.059(95 \% \mathrm{CI}=1.231$ to 3.444; $P=0.006$; Table 3) and $1.803(95 \% \mathrm{CI}=1.101$ to 2.955; $P=0.019$; Table S3). After the adjustment for potential confounding factors, multivariate Cox regression analysis showed that high expression of APOC1 might be an independent prognostic factor in CRC $(\mathrm{HR} .=1.704 ; 95 \%$ $\mathrm{CI}=1.012$ to $2.869 ; P=0.045$; Table 3 ). Thus, these results suggest that APOC1 is highly expressed and upregulated in $\mathrm{CRC}$, and $\mathrm{APOC} 1$ may be predictive for clinicopathological significant events for patients with CRC.

\section{APOCl is overexpressed in CRC cell lines}

We subsequently examined levels of APOC1 expression in five CRC cell lines (SW1116, SW620, HCT116, SW480 

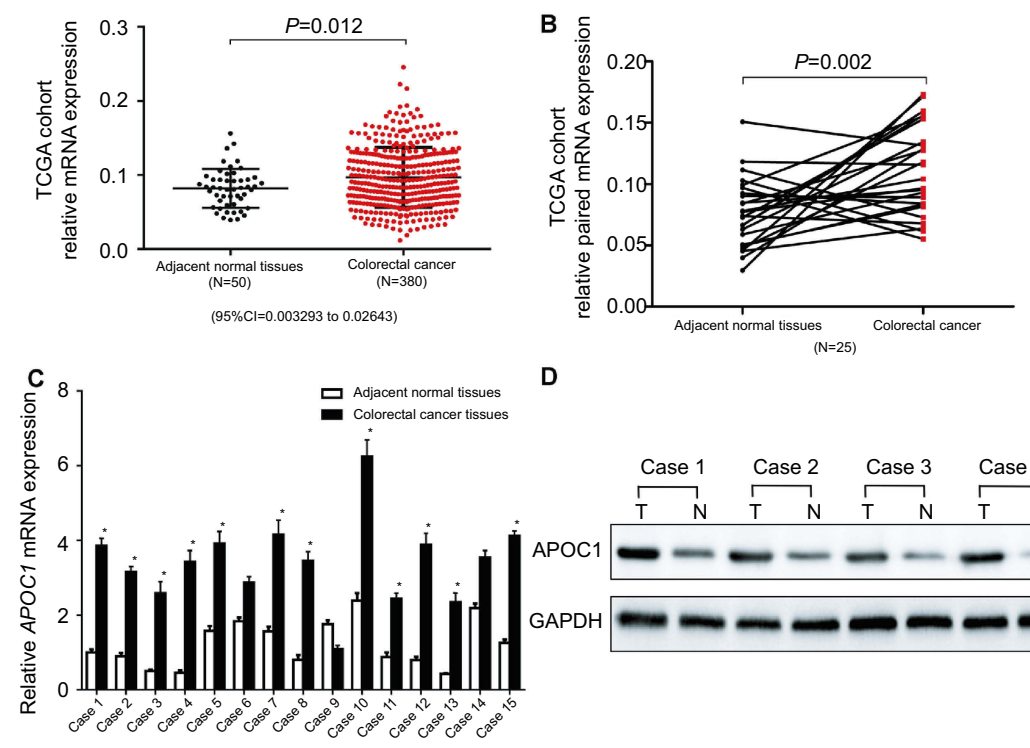

D

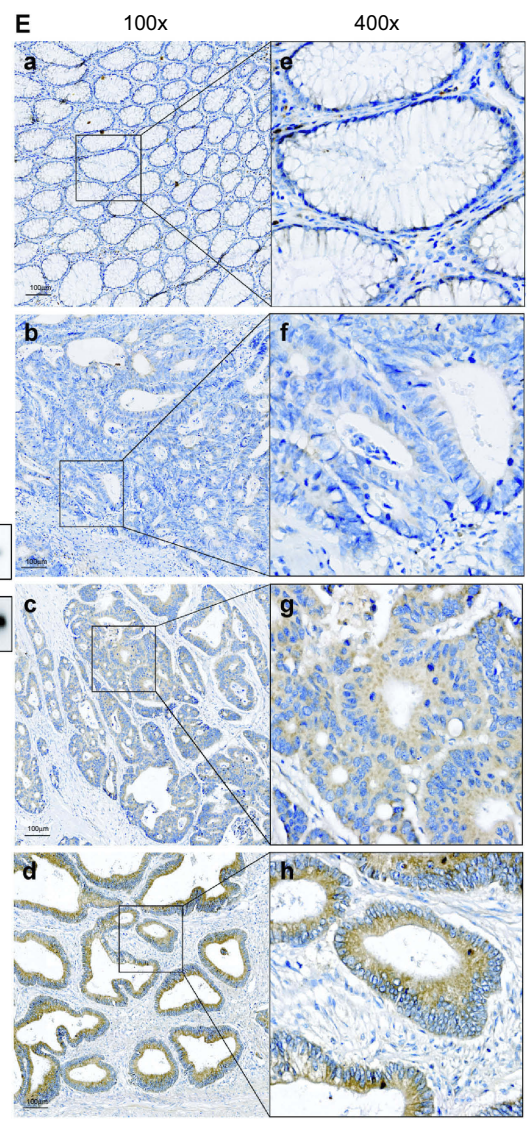

Figure I Apolipoprotein $\mathrm{Cl}(\mathrm{APOCI})$ is overexpressed in primary colorectal cancer (CRC).

Notes: $(A)$ APOCI was highly expressed in CRC $(n=380)$ samples compared to adjacent normal $(n=50)$ samples based on The Cancer Genome Atlas (TCGA) database (unpaired $t$-test, $P=0.012$ ). (B) APOCI was highly expressed in colorectal cancer samples compared to the adjacent normal samples of a matched paired group ( $n=25$ ) based on The Cancer Genome Atlas (TCGA) database (paired $t$-test, $P=0.002$ ). (C) The mRNA expression level of APOCI was higher in the majority of the 15 colorectal cancer tissues compared with the matched adjacent normal tissues (paired $t$-test, $P<0.01$ ). (D) The protein expression level of APOCI was detected by Western blotting. Protein expression was higher in the colorectal cancer tissues (TI-T4) compared with the matched adjacent normal tissues (NI-N4). (E) Immunohistochemical detection of APOCI protein expression in paraffin-embedded tissues. Positive APOCI staining was observed mainly in the cytoplasm of CRC tissues; a and e, APOCI was not detected in normal colorectal tissues; $b$ and $f$, representative images of weak APOCI staining in CRC tissues; $c$ and g, representative images of moderate APOCI staining in CRC tissues; $d$ and $\mathrm{h}$, representative images of strong APOCI staining in CRC tissues; a, b, c, and d, original magnification $\times 100$ (scale bar $=100 \mu \mathrm{M})$; e, f, g, and h, $\times 400$. (F) and (G) KaplanMeier survival analysis according to APOCI expression in 140 patients with CRC. The overall survival (OS) and disease-free survival (DFS) for patients with high versus low APOCI expression. The difference is statistically significant based on the log-rank test (both $P<0.00 \mathrm{I}$ ).

and LS174T) and a human immortalized colonic epithelial cell line (NCM460) by Western blotting and RT-PCR. Western blotting analysis showed that five CRC cell lines had higher protein levels of APOC1 compared with NCM460 (Figure 2A). Similarly, APOC1 mRNA expression was at least fourfold greater in the CRC cell lines compared with NCM460 (Figure 2B). SW480 and SW620 were selected for the following experiments because of the high mRNA and protein expression levels of APOC1.

To determine the potential functions of APOC1 in CRC, SW480 and SW620 cells were transfected with different APOC1 siRNA (si-APOC1\#1-3) oligomers to knock down endogenous APOC1, and a nonspecific siRNA (si-Control) was used as the negative control. APOC1 mRNA and protein expression levels were downregulated by transfection of
APOC1 siRNAs (Figure 2C and D). The si-APOC1\#1, which had a higher knockdown efficiency than si-APOC $1 \# 2-3$, was then used in the following assays.

\section{Silencing of APOCI inhibits CRC cell proliferation}

To clarify the role of APOC1 in cell proliferation, CCK-8 assays and clonogenic assays were performed. The results of the CCK-8 assay suggested that the proliferation rate of silenced APOC1 cells was lower than its control cells (both $P<0.05$, Figure 3A). Moreover, a clonogenic assay indicated that, compared with control cells, silenced APOC 1 cells showed decreased colony formation capacity after 10-14 of days conventional culture (both $P<0.01$, 
Table 2 Oncomine analysis of APOCI expression in colorectal cancer (total 7 colorectal cancer cohorts)

\begin{tabular}{|c|c|c|c|c|}
\hline Cohort number & Cohort & Sample (n) & Fold-change & $P$-value \\
\hline I & Notterman Colon' & Colon adenocarcinoma (18) vs normal (18) & +7.94 & $4.94 \times 10^{-5}$ \\
\hline 2 & Gaspar Colon ${ }^{2}$ & Colorectal adenoma epithelia (56) vs normal (22) & +1.166 & $3.75 \times 10^{-4}$ \\
\hline \multirow[t]{2}{*}{3} & \multirow[t]{2}{*}{ Skrzypczak Colorectal $2^{3}$} & Colon carcinoma (5) vs normal ( 10$)$ & +1.373 & $9.32 \times 10^{-4}$ \\
\hline & & Colon carcinoma epithelia (5) vs normal (10) & +1.551 & $1.76 \times 10^{-5}$ \\
\hline \multirow[t]{6}{*}{4} & \multirow[t]{6}{*}{ Kaiser Colon ${ }^{4}$} & Rectal mucinous adenocarcinoma (4) vs normal (5) & +2.514 & 0.039 \\
\hline & & Cecum adenocarcinoma (17) vs normal (5) & +2.049 & 0.005 \\
\hline & & Rectosigmoid adenocarcinoma (10) vs normal (5) & +1.963 & 0.016 \\
\hline & & Colon adenocarcinoma (4I) vs normal (5) & +1.836 & 0.006 \\
\hline & & Colon mucinous adenocarcinoma (13) vs normal (5) & +4.147 & $7.09 \times 10^{-4}$ \\
\hline & & Rectal adenocarcinoma (8) vs normal (5) & +2.464 & 0.015 \\
\hline \multirow[t]{2}{*}{5} & \multirow[t]{2}{*}{ TCGA Colorectal } & Colon mucinous adenocarcinoma (22) vs normal (22) & +2.135 & $6.42 \times 10^{-4}$ \\
\hline & & Colon adenocarcinoma (10I) vs normal (22) & +1.548 & 0.002 \\
\hline 6 & Hong Colorectal $\left.\right|^{5}$ & Colorectal carcinoma (70) vs normal (12) & +2.028 & 0.011 \\
\hline 7 & Skrzypczak Colorectal ${ }^{3}$ & Colorectal carcinoma (36) vs normal (24) & +1.399 & 0.035 \\
\hline
\end{tabular}

Table 3 Cox regression analysis of potential overall survival factors for patients with colorectal cancer

\begin{tabular}{|c|c|c|c|c|}
\hline \multirow[t]{2}{*}{ Variable } & \multicolumn{2}{|l|}{ Univariate analysis } & \multicolumn{2}{|c|}{ Multivariate analysis } \\
\hline & HR $(95 \% \mathrm{CI})$ & $p$-Value & HR (95\% Cl) & $p$-Value \\
\hline $\begin{array}{l}\text { Age (years) } \\
\text { Gender } \\
\text { Tumor location }\end{array}$ & $\begin{array}{l}0.85 \mathrm{I}(0.5 \mathrm{I} 5 \text { to } \mathrm{I} .408) \\
\mathrm{I} .464(0.885 \text { to } 2.423) \\
\mathrm{I} .080(0.919 \text { to } \mathrm{I} .269)\end{array}$ & $\begin{array}{l}0.531 \\
0.138 \\
0.351\end{array}$ & & \\
\hline $\begin{array}{l}\text { Tumor size } \\
\qquad 5 \mathrm{~cm} \\
\geq 5 \mathrm{~cm}\end{array}$ & $\begin{array}{l}0.556(0.338 \text { to } 0.939) \\
1.000\end{array}$ & $0.028^{\mathrm{a}}$ & & \\
\hline $\begin{array}{l}\text { TNM stage } \\
\text { I } \\
\text { II } \\
\text { III } \\
\text { IV }\end{array}$ & $\begin{array}{l}0.08 \mathrm{I}(0.023 \text { to } 0.280) \\
0.208(0.106 \text { to } 0.408) \\
0.377(0.198 \text { to } 0.719) \\
1.000\end{array}$ & $\begin{array}{l}<0.001^{\mathrm{a}} \\
<0.00 \mathrm{I}^{\mathrm{a}} \\
0.003^{\mathrm{a}}\end{array}$ & $\begin{array}{l}0.094(0.027 \text { to } 0.328) \\
0.222(0.112 \text { to } 0.437) \\
0.385(0.201 \text { to } 0.735) \\
1.000\end{array}$ & $\begin{array}{l}<0.00 \mathrm{I}^{\mathrm{a}} \\
<0.00 \mathrm{I}^{\mathrm{a}} \\
0.004^{\mathrm{a}}\end{array}$ \\
\hline $\begin{array}{l}\text { APOCI expression } \\
\text { High } \\
\text { Low }\end{array}$ & $\begin{array}{l}2.059(1.231 \text { to } 3.444) \\
1.000\end{array}$ & $0.006^{\mathrm{a}}$ & $\begin{array}{l}1.704 \text { (1.012 to } 2.869) \\
1.000\end{array}$ & $0.045^{\mathrm{a}}$ \\
\hline
\end{tabular}

Notes: The TNM staging system is based on the extent of the tumor $(\mathrm{T})$, the extent of spread to the lymph nodes $(\mathrm{N})$ and the presence of metastasis. ${ }^{2}$ Statistically significant.

Figure 3B). Collectively, these results indicated that silencing of APOC1 may inhibit CRC cell proliferation.

\section{Silencing of APOCI induces CRC cell cycle arrest and apoptosis in CRC cells}

We next evaluated the effect of APOC1 knockdown on the cell cycle distribution and apoptosis in CRC cells by flow cytometry. As shown in Figure 3C, silencing of APOC1 was associated with cell accumulation in the G0/G1 phase and decreased in the G2/M phase in SW480 and SW620, respectively, compared with the control cells (both $P<0.05$ ). Subsequently, an apoptosis assay showed that despite statistical differences, silencing APOC1 does not induce biologically significant changes in apoptosis rate. Further, biochemical markers of the cell cycle and apoptosis were detected. Western blot analyses revealed that protein levels of G1 phase-related cyclin D1 and G2 phase-related cyclins B1 


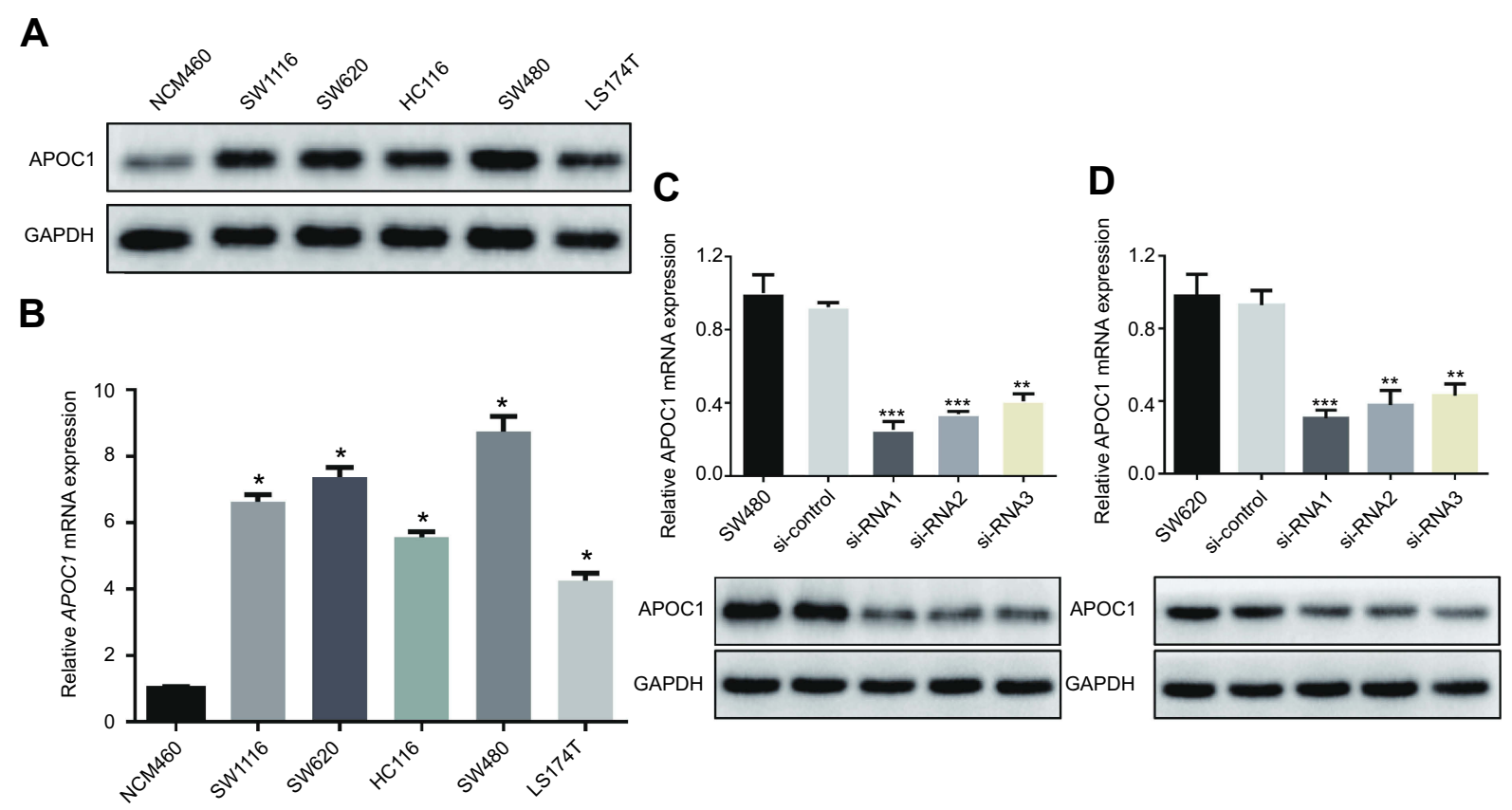

Figure 2 Overexpression of APOCI mRNA and protein in colorectal cancer (CRC) cell lines.

Notes: (A) and (B) Expression of APOCI protein and mRNA in CRC cell lines (SWIII 6, SW620, HCTII6, SW480 and LSI74T) and an immortalized colonic epithelial cell line (NCW460) were examined by Western blotting and qPCR. The expression levels were normalized against GAPDH. The error bars represent the the mean (SD) calculated from three parallel experiments. $* P<0.05$. (C) and (D) Successful knockdown of APOCI in SW480 and SW620 CRC cell lines. qPCR and Western blotting were used to detect APOCI knockdown efficiency in untransfected cells, cells transfected with si-Control (negative control siRNA) and cells transfected with si-RNAI, si-RNA2 and si-RNA3. $* * P<0.01$ and $* * * P<0.001$.

and Bcl-2 were downregulated by silencing of APOC1, while caspase-9 was upregulated (Figure3F). These results suggested that silencing of APOC1 may induce G0/G1 phase cell cycle arrest and apoptosis in CRC.

\section{Silencing of APOCI suppresses CRC cell migration and invasion}

To determine the effects of APOC1 on cell invasion and migration, transwell assays with or without Matrigel were performed. Transwell assays revealed that silencing of APOC1 in SW480 and SW620 cells led to approximately $20-40 \%$ reduction in numbers of migrated and invaded cells compared with si-Control transfected cells $(P<0.01$ and $P<0.05$ ) (Figure 3E). These results indicate that

APOC1 protein may be necessary for cell invasion and migration, and silencing of APOC 1 can efficiently repress the motility of CRC cells, and more in vivo investigation is needed.

\section{Silencing of APOCI suppresses the expression of the phosphorylated form of P38 MAPK}

To identify the possible APOC1-associated pathways in CRC, GSEA was conducted with data from the TCGA COAD-READ dataset. As illustrated in Figure 4A and B and
Figure S1, the heatmap and GSEA enrichment plot showed that APOC1 expression may be associated with extracellular matrix (ECM) receptor interaction and the Toll-like receptor (TLR) signaling pathway and is strongly associated with the mitogenactivated protein kinase (MAPK) signaling pathway.

Based on the above results and other reports, we predicted that APOC1 may promote colorectal carcinogenesis via MAPK signaling pathways. To preliminarily verify this hypothesis, we analyzed MAPK signaling pathway-related proteins in SW480 and SW620 cells at 48 hrs after transfection with or without siRNA by Western blotting. Compared with the blank and si-Control group, the phosphorylated form of p38 MAPK (p-p38) decreased after knockdown of APOC1 protein, whereas no significant changes were observed in phosphorylated-Erk1/2 (p-ERK) and phosphorylated-JNK (p-JNK) (Figure 4C). These results indicated that silencing of APOC1 suppressed p-p38 expression, and APOC1 may be involved in CRC carcinogenesis by activating the p38 MAPK signal pathway.

\section{Discussion}

$\mathrm{CRC}$ is a biologically heterogeneous disease involving various genetic and epigenetic alterations, and numerous molecular variables that contribute to the occurrence of CRC have been characterized. ${ }^{30,31}$ In this study, we 


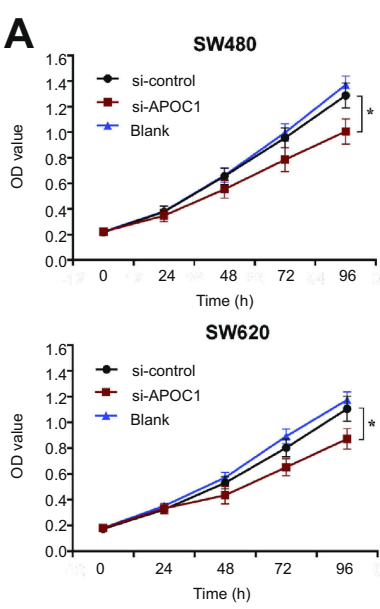

C
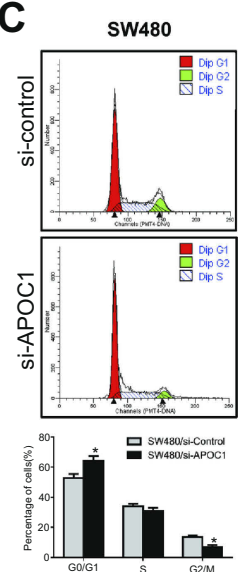
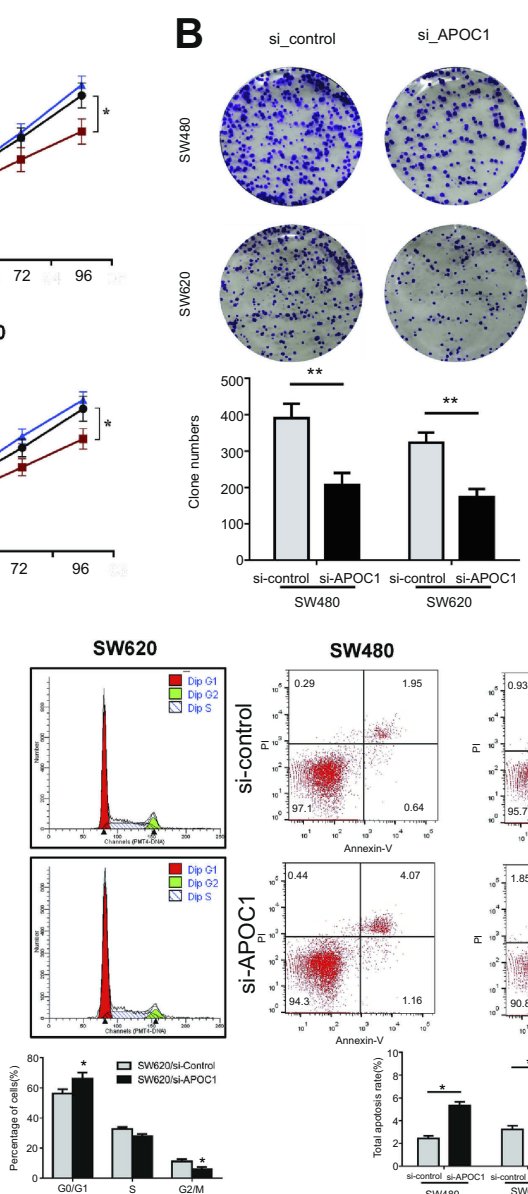

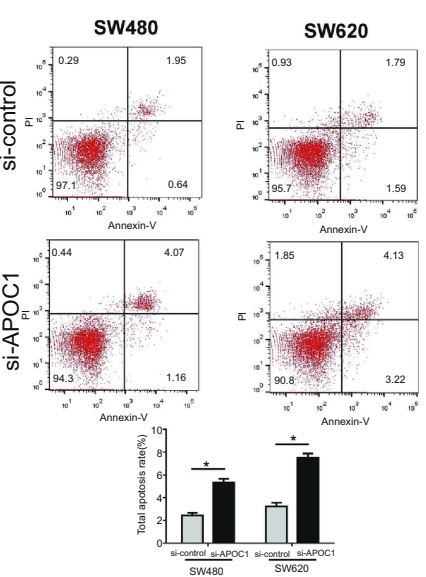

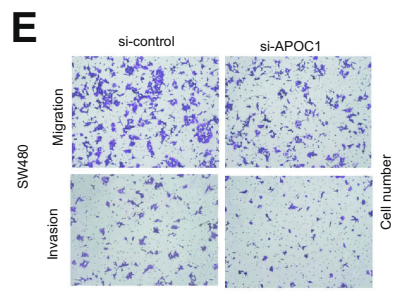
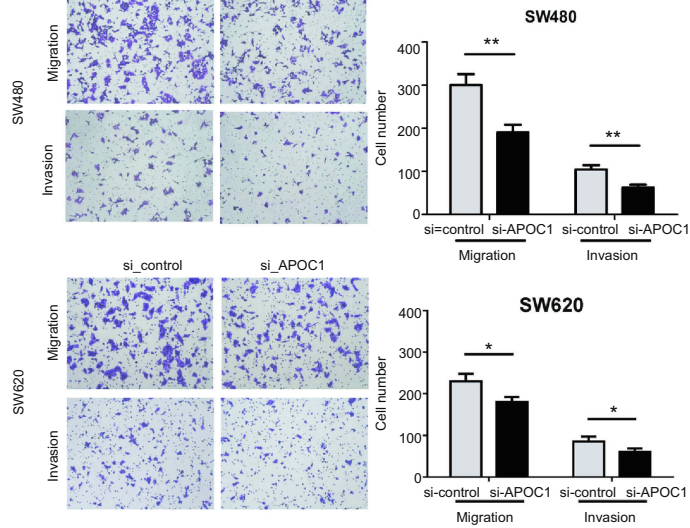

$\mathbf{F}$

Figure 3 Effects of APOCI knockdown on the proliferation, apoptosis, migration and invasion of CRC cells after transfection with si-Control or si-APOCI.

Notes: (A) Cell proliferation of SW480 and SW620 cells was detected using the CCK-8 assay. (B) Representative images of the clonogenic cell survival assays that were performed in SW480 and SW620 cells. (C) Flow cytometry analysis of the proportion of the cells indicated in each stage of the cell cycle (GI, G2 and S) and the percentage of cells in the G0/GI, S and G2/M phase of the cell cycle were quantified and expressed as the mean \pm SD from three independent experiments. (D) Levels of apoptosis in the SW480 and SW620 cells after transfection with si-Control or si-APOCI for 24 hrs. The cells were stained with Annexin V and PI. (E) Cell migration and invasion in SW480 and SW620 cells were assessed using Transwell assay with or without a Matrigel-coated transwell chamber. Magnification, $\times 100$. (F) Detection of Bcl-2, caspase-9, cyclin DI and cyclin BI protein levels by Western blotting. Detection of GAPDH was used as a loading control. Blank: wild-type cells; si-Control: negative control siRNA; siAPOCI: APOCI-siRNA transfected cells $(* P<0.05, * * P<0.01$ Vs si-APOCI).

identified APOC1 as a potential pro-oncogenic protein involved in cell proliferation, migration and invasion of CRC. Our results indicated that APOC1 mRNA and protein expression is higher in CRC tissues and cell lines than in adjacent normal tissues and immortalized colonic epithelial cell lines. Furthermore, we found that APOC1 plays a potential prognostic role in the survival of CRC patients, highlighting the potential values of APOC1 as an independent prognostic biomarker in human CRC. Mechanistically, we used bioinformatic approaches to analyze the possible pathway. We conjectured that APOC1 promotes cell proliferation, migration and invasion through the p38 MAPK signaling pathway.

Previous studies have demonstrated that APOC1 plays an important role in lipid metabolism-related diseases, such as glomerulosclerosis, ${ }^{32}$ cardiovascular disease $^{33}$ diabetes $^{34}$ and Alzheimer's disease. ${ }^{35}$ However, emerging evidence suggests that APOC1 might be used as a new biomarker to evaluate the prognosis of patients with malignant tumors. Patients with higher or positive APOC1 expression showed a worse prognosis and advanced tumor progression in patients with pancreatic cancer, ${ }^{7}$ gastric cancer, ${ }^{36}$ lung cancer $^{37}$ and papillary thyroid carcinoma. ${ }^{8}$ Our study showed that high APOC1 protein levels were correlated with a higher Duke's classification, higher $\mathrm{T}$ stage, higher $\mathrm{N}$ stage, higher $\mathrm{M}$ stage and higher TNM stage (Table 1). Survival analysis demonstrated that patients with high APOC1 expression had shorter survival times than those with low expression (Figure $1 \mathrm{~F}-\mathrm{G}$ ). These results indicate that $\mathrm{AOPC} 1$ is an important molecular marker and prognostic factor for solid tumors. 
A APOC1-higher expression group

APOC1-lower expression group

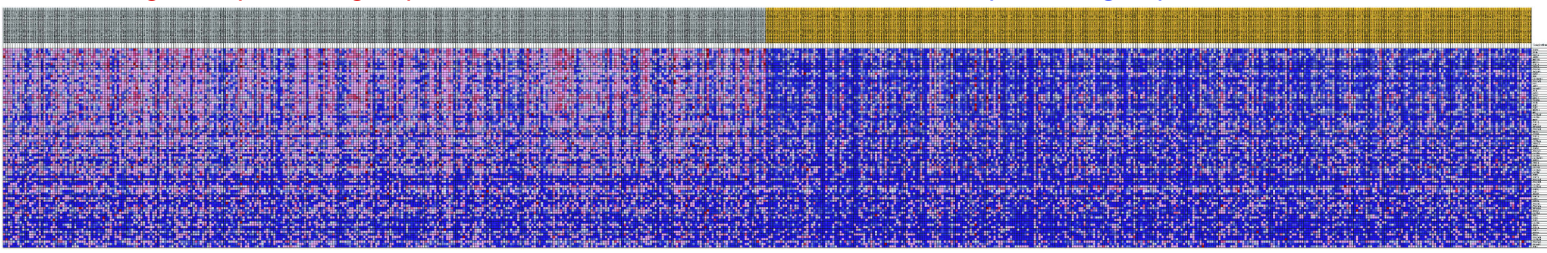

KEGG_MAPK_SIGNALING_PATHWAY

B

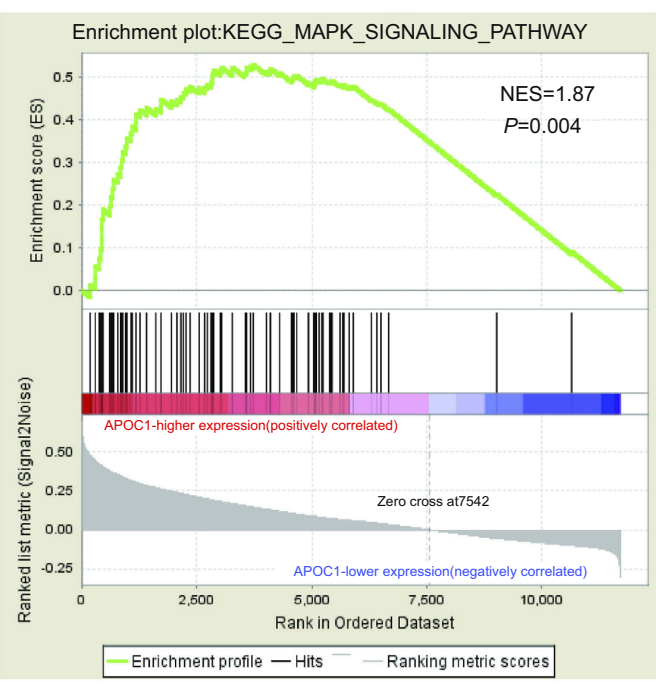

C

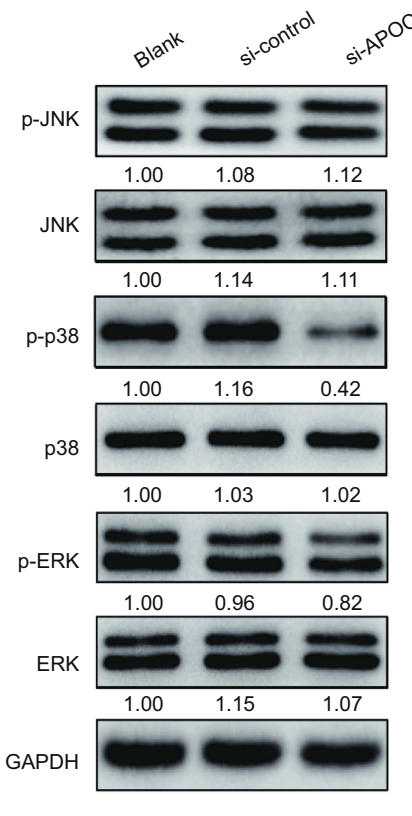

SW480

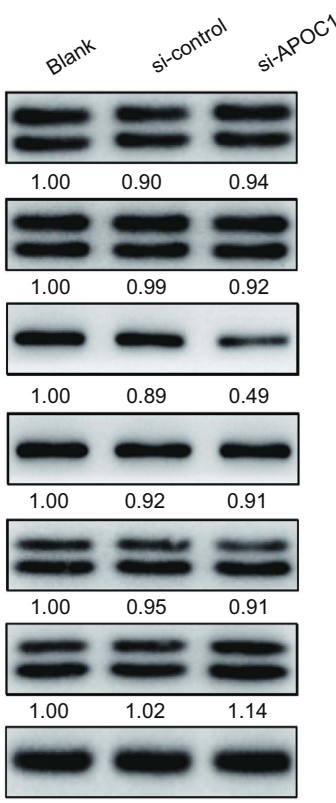

SW620

Figure 4 Silencing of APOCI suppresses the expression of mitogen-activated protein kinase (MAPK) signaling-related genes.

Notes: (A) GSEA-generated heatmap for highly enriched genes in the MAPK signaling pathway in the APOCI-higher expression group compared to the APOCI-lower expression group from the TCGA COAD-READ dataset. (B) GSEA on the TCGA COAD-READ dataset identified MAPK signaling pathways as a regulatory target of APOCI. The GSEA enrichment plot shows values for normalized enrichment score (NES) $=1.87$ and nominal $P$-value $=0.004$. (C) Protein levels of the MAPK pathwayrelated genes were evaluated by Western blotting in SW480 and SW620 cells at 48 hrs after transfection with si-Control or si-APOCI. GAPDH was used as a loading control. Band intensity given underneath gel image was measured using ImageJ software, presented as fold change compared with controls, respectively. Blank: wild-type cells; si-Control: negative control siRNA; si-APOCI: APOCI-siRNA transfected cells.

Engwegen et $\mathrm{al}^{38}$ reported that APOC1 plays a potential role in distinguishing a colon cancer and a healthy control group. Similarly, Yasui et $\mathrm{al}^{39}$ found that compared with normal gastric epithelial cells, APOC1 was upregulated in gastric cancer, as shown by serial analysis of gene expression. Similar to Yasui's report, our study found that APOC1 was highly expressed and upregulated in primary CRC (Figure 1A-E and Figure 2A-B). Trougakos et $\mathrm{al}^{40}$ indicated that knockdown or silencing of apolipoprotein-J in osteosarcoma and prostate cancer cells can significantly inhibit tumor cell proliferation and promote tumor cell apoptosis. In the present study, we found that silencing of APOC1 may attenuate the CRC cell proliferation rate (Figure 3A) and colony formation capacity (Figure 3B) and suggested that silencing of APOC1 may inhibit the proliferation function in CRC. We also found that silencing of APOC1 arrested CRC cells in the G0/G1 phase by flow cytometry (Figure 3C). Our Western blot results showed that cyclin B1 and cyclin D1 protein level were decreased in
APOC1 silenced cells (Figure 3F), and it further confirmed that silencing APOC1 may arrest CRC cells in the G0/G1 phase. Flow cytometry showed that silencing of APOC1 increased CRC cell total apoptosis (Figure 3D) and confirmed the protein levels of caspase-9 and Bcl-2 by Western blotting (Figure 3F). These results suggested that APOC1 may affect cell proliferation of CRC cells by cell cycle arrest and cell apoptosis. Christine et $\mathrm{al}^{41}$ reported that APOC1 was overexpressed in invasive pancreatic carcinoma, as shown by in situ hybridization and speculated that APOC1 overexpression may increase the invasive function of pancreatic carcinoma. Similarly, silencing of APOC1 may attenuate the migration and invasion functions of CRC cells (Figure 3E). It is suggested that APOC1 may also participate in motility of CRC cells and have a promoting function.

It has been reported that APOC1 could function as a potential tumor oncogene in different cancers. ${ }^{5-7}$ Some reports showed that APOC1 can activate or inhibit some 
kinases to regulate physiological or pathological functions, which were correlated with the genesis and development of cancers. However, the mechanism of APOC1 in cancers is not yet elucidated. Takano et $\mathrm{al}^{7}$ reported that APOC1 can affect preinvasive carcinoma by an autocrine function. In addition, it has been proved that APOC1 secreted as an autocrine was necessary for tumor cell survival and malignant phenotype. Thus, APOC1 may inhibit cells apoptosis to affect tumorigenesis and development. In contrast, a report ${ }^{42}$ indicated that APOC1 peptides can inhibit cell proliferation and promote apoptosis in breast cancer cells in vitro and suppress tumor growth in nude mice, but the mechanism was unconfirmed. To explore the molecular mechanism by which APOC1 exerted its functions on CRC, we performed GSEA on the TCGA COAD-READ dataset. GSEA is a bioinformatic approach that can analyze the possible correlation of a target gene and known functional gene sets. ${ }^{23}$ GSEA showed that many cancer-related gene sets, including ECM receptor interaction, the TLR pathway and MAPK pathways, were positively correlated with APOC1 expression (Figure 4A and B and Figure $\mathrm{S} 1)$. Through further analysis, we found that the apolipoprotein family could trigger MAPK signaling pathways to cause cell proliferation, ${ }^{43}$ apoptosis ${ }^{44}$ and invasion. ${ }^{45}$ So, we conjectured that APOC1 may be associated with MAPK signaling pathways in $\mathrm{CRC}^{46,47}$ and further validated by immunoblotting (Figure 4C) that knockdown of APOC1 may decrease the phosphorylation of p38 without obviously changing total ERK1/2, p38, JNK1/2/3, phosphorylated-ERK1/2 and phosphorylated-JNK1/2/3. We initially conjectured that silencing APOC1 in CRC may inactivate the p38MAPK pathway to attenuate $\mathrm{CRC}$ cell proliferation, migration and invasion. Thus, we conjectured that APOC1 could promote CRC cell proliferation, migration and invasion via the MAPK pathway.

\section{Conclusion}

This study demonstrated that APOC1 was overexpressed in CRC tissues and that a high level of APOC1 contributed to a poor prognosis. APOC1 expression influenced the cell proliferation ability and motility capacity of $\mathrm{CRC}$ via the MAPK pathway. Our findings suggest that APOC1 could be used as a prognostic biomarker in $\mathrm{CRC}$, although further investigation is needed.

\section{Acknowledgments}

This study was supported by grants from the Natural Science Foundation of Guangdong Province (2017A030310194 and 2017A030310215), Science and Technology Planning Project of Guangdong Province (2016A020216008), Medical
Scientific Research Foundation of Guangdong Province (A2017267 and A2017274), and Administration of Traditional Chinese Medicine of Guangdong Province, China (20151162)

\section{Author contributions}

All authors contributed toward data analysis, drafting and revising the paper, gave final approval of the version to be published and agree to be accountable for all aspects of the work.

\section{Disclosure}

The authors report no conflicts of interest in this work.

\section{References}

1. Fitzmaurice C, Allen C, Barber RM, et al. Global, regional, and national cancer incidence, mortality, years of life lost, years lived with disability, and disability-adjusted life-years for 32 cancer groups, 1990 to 2015: a systematic analysis for the global burden of disease study. JAMA Oncol. 2017;3(4):524-548.

2. Stewart BW, Wild C. World Cancer Report 2014 [M]. Lyon, France International Agency for Research on Cancer, 2014:16-53.

3. Siegel RL, Miller KD, Fedewa SA, et al. Colorectal cancer statistics, 2017. CA Cancer J Clin. 2017;67(3):177-193. doi:10.3322/caac.21395

4. Jong MC, Hofker MH, Havekes LM. Role of ApoCs in lipoprotein metabolism: functional differences between $\mathrm{ApoC} 1, \mathrm{ApoC} 2$, and ApoC3. Arterioscler Thromb Vasc Biol. 1999;19(3):472-484.

5. Zhang J, Guo F, Wang L, et al. Identification of apolipoprotein C-I as a potential Wilms' tumor marker after excluding inflammatory factors. Int J Mol Sci. 2014;15(9):16186-16195. doi:10.3390/ijms150916186

6. Moore LE, Brennan P, Karami S, et al. Apolipoprotein E/C1 locus variants modify renal cell carcinoma risk. Cancer Res. 2009;69 (20):8001-8008. doi:10.1158/0008-5472.CAN-09-1734

7. Takano S, Yoshitomi H, Togawa A, et al. Apolipoprotein C-1 maintains cell survival by preventing from apoptosis in pancreatic cancer cells. Ongogene. 2008;27(20):2810-2822. doi:10.1038/sj.onc.1210951

8. Fan Y, Shi L, Liu Q, et al. Discovery and identification of potential biomarkers of papillary thyroid carcinoma. Mol Cancer. 2009;8:79. doi:10.1186/1476-4598-8-79

9. Jong MC, van Dijk KW, Dahlmans VE, et al. Reversal of hyperlipidaemia in apolipoprotein $\mathrm{C} 1$ transgenic mice by adenovirus-mediated gene delivery of the low-density-lipoprotein receptor, but not by the very-lowdensity-lipoprotein receptor. Biochem J. 1999;338(Pt 2):281-287.

10. Jong MC, Dahlmans VE, van Gorp PJ, et al. In the absence of the low density lipoprotein receptor, human apolipoprotein $\mathrm{C} 1$ overexpression in transgenic mice inhibits the hepatic uptake of very low density lipoproteins via a receptor-associated protein-sensitive pathway. J Clin Invest. 1996;98(10):2259-2267. doi:10.1172/JCI119036

11. Zhang H, Liang B, Li T, et al. Orexin A suppresses oxidized LDL induced endothelial cell inflammation via MAPK p38 and NF-kappaB signaling pathway. IUBMB Life. 2018;70(10):961-968. doi:10.1002/iub.1890

12. Li W, Zhi W, Zhao J, et al. Cinnamaldehyde protects VSMCs against ox-LDL-induced proliferation and migration through $\mathrm{S}$ arrest and inhibition of p38, JNK/MAPKs and NF-kappaB. Vascul Pharmacol. 2018;108:57-66. doi:10.1016/j.vph.2018.05.005

13. Wang X, Mao R, Chen W. FSD-C10 shows therapeutic effects in suppressing oxidized low-density lipoprotein (ox-LDL)-induced human brain microvascular endothelial cells apoptosis via Rho-Associated Coiled-Coil Kinase (ROCK)/Mitogen-Activated Protein Kinase (MAPK) Signaling. Med Sci Monit. 2018;24:5509-5516. doi:10.12659/MSM.911481 
14. Wang S, Zhou H, Feng T, et al. beta-Glucan attenuates inflammatory responses in oxidized LDL-induced THP-1 cells via the p38 MAPK pathway. Nutr Metab Cardiovasc Dis. 2014;24(3):248-255. doi:10.1016/j.numecd.2013.09.019

15. Cargnello M, Roux PP. Activation and function of the MAPKs and their substrates, the MAPK-activated protein kinases. Microbiol Mol Biol Rev. 2011;75(1):50-83. doi:10.1128/MMBR.00031-10

16. Waetzig V, Herdegen T. Neurodegenerative and physiological actions of c-Jun N-terminal kinases in the mammalian brain. Neurosci Lett. 2004;361(1-3):64-67. doi:10.1016/j.neulet.2004.02.041

17. Johnson GL, Lapadat R. Mitogen-activated protein kinase pathways mediated by ERK, JNK, and p38 protein kinases. Science. 2002;298 (5600):1911-1912. doi:10.1126/science.1072682

18. Chen Z, Cobb MH. Regulation of stress-responsive mitogen-activated protein (MAP) kinase pathways by TAO2. J Biol Chem. 2001;276 (19):16070-16075. doi:10.1074/jbc.M100681200

19. Xu K, Song X, Chen Z, et al. XRCC2 promotes colorectal cancer cell growth, regulates cell cycle progression, and apoptosis. Medicine (Baltimore). 2014;93(28):e294. doi:10.1097/MD.0000000000000294

20. Li C, Cao L, Xu C, et al. The immunohistochemical expression and potential prognostic value of HDAC6 and AR in invasive breast cancer. Hum Pathol. 2018;75:16-25. doi:10.1016/j.humpath.2017.11.010

21. Xu K, Chen Z, Cui Y, et al. Combined olaparib and oxaliplatin inhibits tumor proliferation and induces $\mathrm{G} 2 / \mathrm{M}$ arrest and gamma-H2AX foci formation in colorectal cancer. Onco Targets Ther. 2015;8:3047-3054. doi:10.2147/OTT.S89154

22. Qin CJ, Song XM, Chen ZH, et al. XRCC2 as a predictive biomarker for radioresistance in locally advanced rectal cancer patients undergoing preoperative radiotherapy. Oncotarget. 2015;6(31):32193-32204. doi:10.18632/oncotarget.4975

23. Subramanian A, Tamayo P, Mootha VK, et al. Gene set enrichment analysis: a knowledge-based approach for interpreting genome-wide expression profiles. Proc Natl Acad Sci U S A. 2005;102 (43):15545-15550. doi:10.1073/pnas.0506580102

24. Subramanian A, Kuehn H, Gould J, et al. GSEA-P: a desktop application for Gene Set Enrichment Analysis. Bioinformatics. 2007;23 (23):3251-3253. doi:10.1093/bioinformatics/btm369

25. Notterman DA, Alon U, Sierk AJ, et al. Transcriptional gene expression profiles of colorectal adenoma, adenocarcinoma, and normal tissue examined by oligonucleotide arrays. Cancer Res. 2001;61(7):3124-3130.

26. Gaspar C, Cardoso J, Franken P, et al. Cross-species comparison of human and mouse intestinal polyps reveals conserved mechanisms in adenomatous polyposis coli (APC)-driven tumorigenesis. $\mathrm{Am}$ J Pathol. 2008;172(5):1363-1380. doi:10.2353/ajpath.2008.070851

27. Skrzypczak M, Goryca K, Rubel T, et al. Modeling oncogenic signaling in colon tumors by multidirectional analyses of microarray data directed for maximization of analytical reliability. PLoS One. 2010;5(10). doi:10.1371/annotation/8c585739-a354$4 \mathrm{fc} 9-\mathrm{a} 7 \mathrm{~d} 0-\mathrm{d} 5 \mathrm{ae} 26 \mathrm{fa} 06 \mathrm{ca}$

28. Kaiser S, Park YK, Franklin JL, et al. Transcriptional recapitulation and subversion of embryonic colon development by mouse colon tumor models and human colon cancer. Genome Biol. 2007;8(7): R131. doi:10.1186/gb-2007-8-5-r81

29. Hong Y, Downey T, Eu KW, et al. A 'metastasis-prone' signature for early-stage mismatch-repair proficient sporadic colorectal cancer patients and its implications for possible therapeutics. Clin Exp Metastasis. 2010;27(2):83-90. doi:10.1007/s10585-010-9305-4

30. Budinska E, Popovici V, Tejpar S, et al. Gene expression patterns unveil a new level of molecular heterogeneity in colorectal cancer. J Pathol. 2013;231(1):63-76. doi:10.1002/path.4212

31. Gundert M, Edelmann D, Benner A, et al. Genome-wide DNA methylation analysis reveals a prognostic classifier for non-metastatic colorectal cancer (ProMCol classifier). Gut. 2019;68:101-110.
32. Bus P, Pierneef L, Bor R, et al. Apolipoprotein C-I plays a role in the pathogenesis of glomerulosclerosis. J Pathol. 2017;241(5):589-599. doi:10.1002/path.4859

33. Moore D, McNeal C, Macfarlane R. Isoforms of apolipoprotein C-I associated with individuals with coronary artery disease. Biochem Biophys Res Commun. 2011;404(4):1034-1038.

34. Bouillet B, Gautier T, Blache D, et al. Glycation of apolipoprotein C1 impairs its CETP inhibitory property: pathophysiological relevance in patients with type 1 and type 2 diabetes. Diabetes Care. 2014;37 (4):1148-1156. doi:10.2337/dc13-1467

35. Seripa D, Bizzarro A, Pilotto A, et al. TOMM40, APOE, and APOC1 in primary progressive aphasia and frontotemporal dementia. $J$ Alzheimers Dis. 2012;31(4):731-740. doi:10.3233/JAD-2012-120403

36. Cohen M, Yossef R, Erez T, et al. Serum apolipoproteins C-I and C-III are reduced in stomach cancer patients: results from MALDI-based peptidome and immuno-based clinical assays. PLoS One. 2011;6(1):e14540. doi:10.1371/journal.pone.0014540

37. Ko HL, Wang YS, Fong WL, et al. Apolipoprotein C1 (APOC1) as a novel diagnostic and prognostic biomarker for lung cancer: A marker phase I trial. Thorac Cancer. 2014;5(6):500-508. doi:10.1111/17597714.12117

38. Engwegen JY, Helgason HH, Cats A, et al. Identification of serum proteins discriminating colorectal cancer patients and healthy controls using surface-enhanced laser desorption ionisation-time of flight mass spectrometry. World $J$ Gastroenterol. 2006;12 (10):1536-1544.

39. Yasui W, Oue N, Ito R, et al. Search for new biomarkers of gastric cancer through serial analysis of gene expression and its clinical implications. Cancer Sci. 2004;95(5):385-392.

40. Trougakos IP, So A, Jansen B, et al. Silencing expression of the clusterin/apolipoprotein $\mathrm{j}$ gene in human cancer cells using small interfering RNA induces spontaneous apoptosis, reduced growth ability, and cell sensitization to genotoxic and oxidative stress. Cancer Res. 2004;64(5):1834-1842.

41. Iacobuzio-Donahue CA, Ryu B, Hruban RH, et al. Exploring the host desmoplastic response to pancreatic carcinoma: gene expression of stromal and neoplastic cells at the site of primary invasion. Am J Pathol. 2002;160(1):91-99. doi:10.1016/S0002-9440(10) 64353-2

42. Sun Y, Zhang J, Guo F, et al. Identification of apolipoprotein C-I peptides as a potential biomarker and its biological roles in breast cancer. Med Sci Monit. 2016;22:1152-1160.

43. Ma XL, Gao XH, Gong ZJ, et al. Apolipoprotein A1: a novel serum biomarker for predicting the prognosis of hepatocellular carcinoma after curative resection. Oncotarget. 2016;7(43):70654-70668. doi:10.18632/oncotarget.12203

44. Sol EM, Sundsten T, Bergsten P. Role of MAPK in apolipoprotein CIII-induced apoptosis in INS-1E cells. Lipids Health Dis. 2009;8:3. doi:10.1186/1476-511X-8-49

45. Jayakar SK, Loudig O, Brandwein-Gensler M, et al. Apolipoprotein E promotes invasion in oral squamous cell carcinoma. Am J Pathol. 2017;187(10):2259-2272. doi:10.1016/j.ajpath.2017.06.016

46. Han HB, Gu J, Ji DB, et al. PBX3 promotes migration and invasion of colorectal cancer cells via activation of MAPK/ERK signaling pathway. World J Gastroenterol. 2014;20(48):18260-18270. doi:10.3748/wjg.v20. i48.18260

47. Tian XQ, Guo FF, Sun DF, et al. Downregulation of ZNF278 arrests the cell cycle and decreases the proliferation of colorectal cancer cells via inhibition of the ERK/MAPK pathway. Oncol Rep. 2017;38(6):3685-3692. doi:10.3892/or.2017.6031 


\section{Supplementary materials}

A APOC1-higher expression group

APOC1-lower expression group

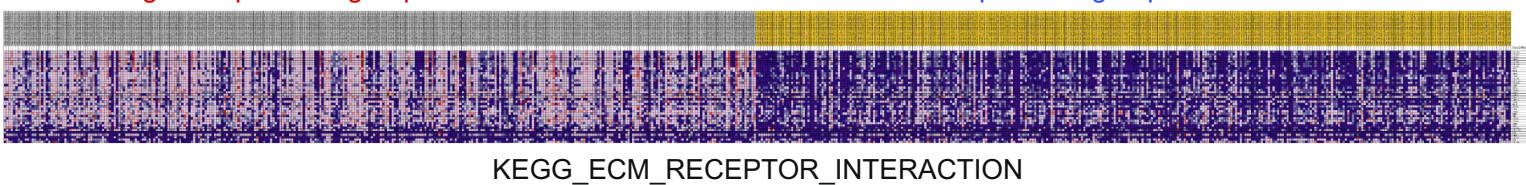

APOC1-higher expression group

APOC1-lower expression group

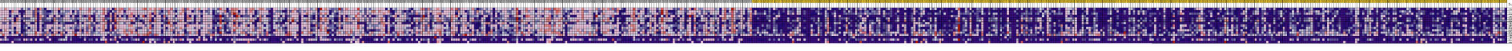 \\ KEGG_TOLL_LIKE_RECEPTOR_SIGNALING_PATHWAY}

B
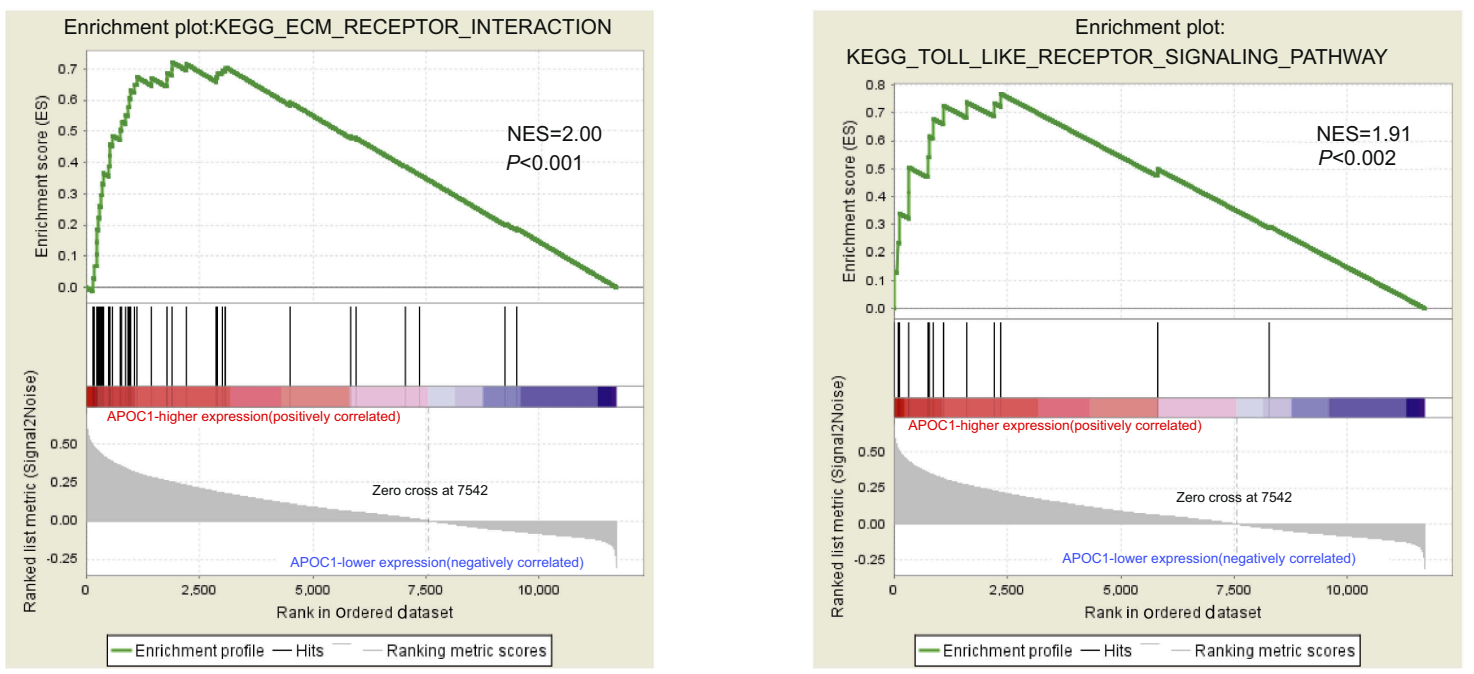

Figure SI Gene set enrichment analysis (GSEA) enrichment analysis of the co-expressed genes.

Notes: (A) GSEA-generated heatmap for highly enriched genes in extracellular matrix (ECM) receptor interaction and the Toll-like receptor (TLR) signaling pathway on APOCI-higher expression group compared to the APOCl-lower expression group from the TCGA COAD-READ dataset. (B) GSEA on the TCGA COAD-READ dataset identified ECM receptor interaction and the TLR signaling pathway as regulatory targets of APOCI. The GSEA enrichment plot shows values for normalized enrichment score $(\mathrm{NES})=2.00$, NES $=1.91$ and $P<0.001, P=0.002$.

Table SI Small interfering RNA (siRNA) sequences that target apolipoprotein CI (si-APOCI) and negative control siRNA (si-Control)

\begin{tabular}{|l|l|l|}
\hline siRNA & Sense sequence $\left(\mathbf{5}^{\prime} \mathbf{-} \mathbf{3} \mathbf{3}^{\prime} \mathbf{)}\right.$ & Antisense sequence(5'- 3') \\
\hline si-APOCI \#I & GAAACACACTGGAGGACAA & CUUUGUGUGACCUCCUGUU \\
si-APOCI \#2 & ATTTCGGTGACTTCCGCATC & UAAAGCCACUGAAGGCGUAG \\
si-APOCI \#3 & TGGGACACAGGCAGGTTCT & ACCCUGUGUCCGUCCAAGA \\
si-Control & UUCUCCGAACGUGUCACGU & AAGAGGCUUGCACAGUGCA \\
\hline
\end{tabular}

Table S2 PCR primers for APOCI and downstream target genes

\begin{tabular}{|l|l|}
\hline Gene & Sequence \\
\hline GAPDH-F & CGCTGAGTACGTCGTGGAGTC \\
GAPDH-R & GCTGATGATCTTGAGGCTGTTGTC \\
APOCI-F & ACCCACTT AGAGTTGTGAGCCC \\
APOCI-R & CAGACCACCTTAGTCCCTTTCC \\
\hline
\end{tabular}


Table S3 Cox regression analysis of potential diseases free survival factors for patients with colorectal cancer

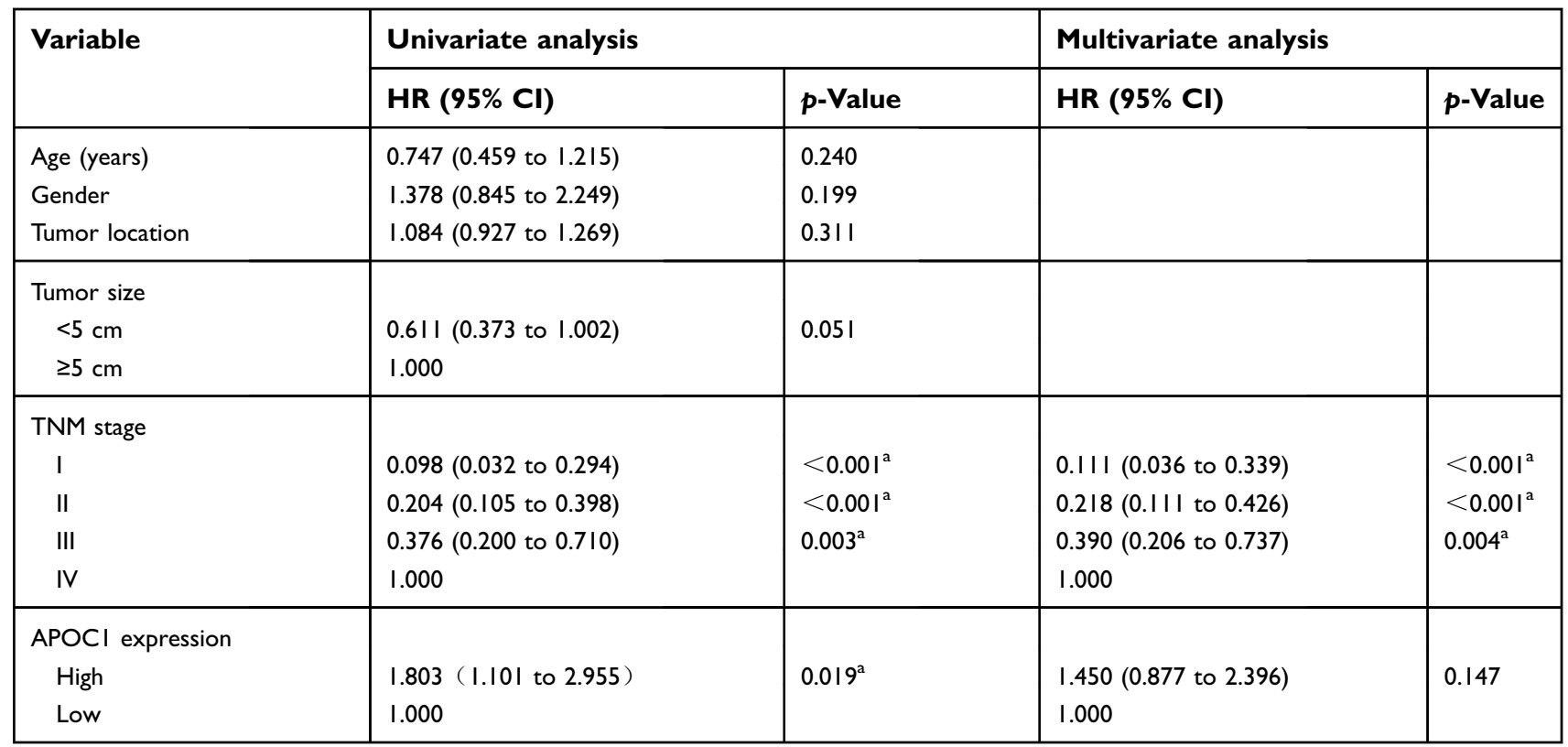

Notes: The TNM staging system is based on the extent of the tumor $(\mathrm{T})$, the extent of spread to the lymph nodes $(\mathrm{N})$ and the presence of metastasis (M). ${ }^{\text {a }}$ Statistically significant.

\section{Publish your work in this journal}

Cancer Management and Research is an international, peer-reviewed open access journal focusing on cancer research and the optimal use of preventative and integrated treatment interventions to achieve improved outcomes, enhanced survival and quality of life for the cancer patient.
The manuscript management system is completely online and includes a very quick and fair peer-review system, which is all easy to use. Visit http://www.dovepress.com/testimonials.php to read real quotes from published authors. 